\title{
Engaging Gifted Science Students through Astronomy
}

\author{
Robert Hollow \\ Australia Telescope National Facility \\ E-mail: Robert.Hollow@csiro.au
}

Astronomy is a subject that poses many deep questions that intrigue students. It can effectively engage gifted and talented science students in their school years. Numerous international and Australian schemes utilize astronomy as a means of challenging and extending such students. Using Gagné's definition, gifted students have potential distinctly above average in one or more of the domains; intellectual, creative, social and physical. Talented students exhibit skills that are distinctly above average in an area of human performance. Such students may comprise about $10-15 \%$ of age peers in that field. They may be identified through a variety of means; by teacher, parent or self, sometimes via diagnostic tests, at others through participation in hobbies or other interests.

Given a student is gifted in science, why should we try and engage them through special programs or extension work? The reasons are many and include pragmatic ones. These students comprise our future professional astronomers, scientists and engineers. Even if they do not aspire to a career in science, it is vital for society to have scientifically literate leaders, managers and lawyers. Developing relevant and engaging experiences fosters positive views of Science. It should also result in more positive interactions in the classroom and at school, with improved educational outcomes overall. Another less measurable but equally worthwhile reason can arise when students experience a breakthrough or wow moment when they internally connect several strands of knowledge together to explain some event or observation. Successful programs for gifted school students require an emphasis on learning concepts and higherorder thinking skills. Problem-based learning activities incorporating the use of technology as a learning tool can be used to model the scientific process. Astronomy is a discipline that lends itself to engage the gifted student and help develop their skills so that they emerge as a talented student. It tackles big questions that many students find challenging and provides a context-rich learning environment. Skills in problem-solving, mathematics, science, literacy, and information and communication technologies (ICT) can be developed given appropriate tasks.

There are a wide range of programs and activities already developed suitable for students at all stages of schooling. Relevant approaches include one-off events such as a guest speaker, extension work within the normal class environment or by withdrawal within the school and the use of extra-curricular opportunities such as a school astronomy club. In-school extension schemes can be a very effective method of engaging a streamed group or individuals but require considerable teacher enthusiasm, expertise, and a supportive, flexible school environment. Other possibilities include specialist camps or summer schools such as the six-week residential Summer Science Program. This successful American scheme is project-based, with students working in teams to plan conduct and 
analyze data to determine an asteroids orbital elements. It has a strong focus on mathematics, physics and astronomy plus an emphasis on social interactions for students.

The option of students taking one or more university courses prior to completing secondary education is available in some countries and states. Perhaps a better approach pedagogically is to develop specific advanced courses that cater for gifted students within an education district or state curriculum. Such curriculum-based schemes exist in several countries. One example is the Cosmology Distinction Course [see previous paper], a matriculation-level subject that has run for the last ten years in NSW, Australia. Students meet at two residentials and complete assignments, exams and a major project of their own choosing. Delivered via distance-education, with provision for extensive student and staff communication via the internet, it allows students from across the state to study the course. A more recent online education initiative is the Cyber Astronomy Course run by Hong Kong University of Science and Technology for senior high school students. Together, such schemes show the power of computer technology in fostering student communication and course delivery.

One key method of engaging students and fostering skill development is that of student research projects. In getting students to tackle a research project we are asking them to actually do some science rather than just repeat textbook experiments. Modern technology plus schemes such as Hands-On Universe, Telescopes in Education, the Charles Sturt Remote Telescope, the Faulkes Telescope Project and others provide opportunities for students and teachers to use powerful CCD/telescope combinations to obtain real and worthwhile data for such projects ranging from simple one-off observations to more advanced, long-term ones. There is considerable scope for institutional support and professional mentors for groups tackling projects and this can also foster beneficial links within a local educational community. Some projects also lend themselves to local or global collaborations among student groups. This adds to the educational value of the task. A common mistake for teachers involved in setting up such a scheme is to artificially impose a limitation on students' abilities and efforts. Gifted and talented students have a habit of rapidly exceeding our preconceptions. This does not mean, however, that there is no place for a structured approach. The use of a scaffold of concepts and task requirements by students provides guidance and support, and increases the educational value of the project.

A scheme run for several years at Blue Mountains Grammar School in NSW saw numerous students tackle astronomy-based projects on topics ranging from naked-eye meteor observations, differential CCD photometry of short-period variables and quasars, $\mathrm{mm}$-wave observations of Orion $\mathrm{A}$, and investigations of LMC regions N159 and N160 using data from the Australia Telescope Compact Array. Follow-up surveys of students showed that a high percentage of them continued in science/technology study and career paths. Even those who went into other fields commented favorably on their research project as a mechanism for improving their ICT, time and project management skills. All gained in confidence and had a positive attitude towards science. Some had benefit in terms of scholarships for university entry. Negative aspects included conflicts with the demands of other subjects, the fact that research skills were not examined in the 
external final examination and the heavy time commitment from both students and teachers.

Numerous case studies suggest the value of specific schemes for gifted and talented students. Ongoing educational evaluation of effective and ineffective programs is needed. Educators and astronomers should identify those that work to model and extend their use. This requires strong linkages between professional and educational groups so that engaging, relevant programs can be developed. An emphasis on teacher training and ongoing support will help raise awareness, confidence and skills. 